\title{
THE COST ASPECT OF MEDICAL EXPERT WITNESSES AND THE POSSIBLE INTRODUCTION OF A MEDICAL EXPERT WITNESS PANEL IN SOUTH AFRICA
}

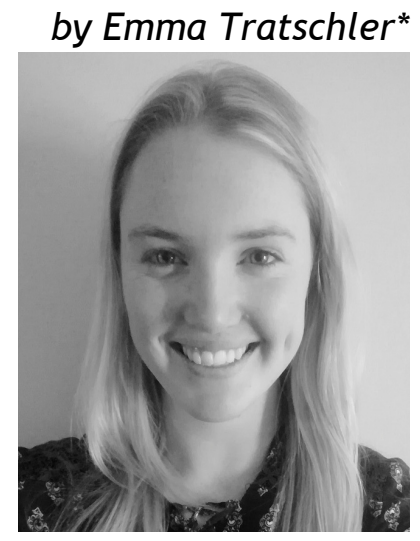

\section{Introduction}

Expert witnesses are often crucial when it comes to court cases. They can possibly be the difference between winning and losing a case. However, expert witnesses are not readily available to every person who wishes to use them. In order to make use of an expert witness, one has to pay the expert an amount set out in the Government Gazette $^{1}$ and the Labour Relations Act. ${ }^{2}$

However, what happens when you need an expert witness, but you cannot afford one? Lawyers are required to do a certain number of hours pro bono work per calendar year, the number of which is set out in the Attorneys Act. ${ }^{3}$ Should medical professionals also be required to work pro bono a certain number of hours a year to be used as expert witnesses?

* $\quad$ Final year LLB student at the University of Pretoria. This article is underscored by the importance of expect witnesses on court cases but also the realisation that expert witnesses are often beyond the means of those who need them. An analogy is drawn between the pro bono work that legal practitioners must do and the idea that medical practitioners can serve as expert witnesses as part of their pro bono work. This article will critically evaluate whether medical practitioners should be required to give themselves a certain number of pro bono hours to serve as expert witnesses.

1 South Africa (2014) Labour Relations Amendment Act. (Proclamation No. R. 87, 2014) Government Gazette 10336: 594, December 19, Regulation No. 38317.

2 Labour Relations Act 66 of 1995.

3 Attorneys Act 53 of 1979. 
The implementation of these pro bono hours would help inadequately resourced litigants to utilise expert witnesses and enable them to fully utilise the allowance of witnesses in the South African legal system.

Expert witnesses are often detrimental to the legal process as they have no legal knowledge and no idea how a court functions. Often expert witnesses, instead of providing information to the court as a whole, provide testimony that is aimed at helping the party who employed them. Considering the judge in many matters is not learned on the matter at hand, this one-sided testimony can be harmful to the case. A multitude of sources will be examined in order to assist in putting forward the idea of a panel of expert witnesses, this will include an analysis of the so-called 'hired gun phenomenon' as well as international sources which may pave the way for South Africa to follow suit.

When looking at the cost of medical expert witnesses and the question of whether, like attorneys, medical professionals should be required to give of themselves a certain number of hours pro bono per year to be used as expert witnesses, I will critically analyse the cost aspect of expert witnesses and weigh it up against the need for expert witnesses for those who cannot afford one.

\section{An examination into whether the costs of medical expert witnesses negatively affect the cases of those who cannot afford to hire one}

\subsection{Costs}

Expert witnesses, although often extremely useful, are not free. The costs of hiring an expert witness are set out in the Government Gazette pursuant to the Labour Relations Act, Regulations of 1995. The witness fee is R300 per day as well as reasonable travelling costs that may be involved. ${ }^{4}$

There are other sources that set out the costs, specifically for witnesses in civil and criminal cases, as well as for psychiatrists, and clinical psychologists. The latter two categories are of particular importance as they relate to medical professionals.

The guideline divides the fees into subsistence allowance, transport and travelling expenses and income forfeited. According to this guideline on witness fees payable in civil cases, the subsistence 
amount includes any expenses if the witness needs to hire accommodation for the night, as well as R50, or any expenses that were reasonably incurred for meals. It goes on to say that the above allowances are payable to the witness for the period that the witness is absent from their home, to attend court. The travelling expenses of a witness in a civil case are as follows: A witness may use private transport, in which case the expenses will be 92c per $\mathrm{km}$ in case of a motorcycle; or R1,30 per $\mathrm{km}$ in case of a motor vehicle, calculated along the shortest route. ${ }^{5}$ In the case of a witness making use of public transport, the travelling expenses are 'an amount equal to the fare for the least expensive transport along the shortest route' ${ }_{7}^{6}$ Lastly, the income forfeited fees the guideline provides as follows: ${ }^{7}$

On satisfactory proof having been produced that a witness has forfeited income as a result of his/her attendance of a civil case, he/ she is entitled to an allowance equal to the actual amount of income so forfeited, to a maximum of R1 500 per day.

The above indicates the fees in respect of witnesses in civil cases.

The fees payable for witnesses in criminal cases differ from the above. They too are set out in the guideline and they are as follows: The subsistence amount includes any expenses if the witness needs to hire accommodation for the night, as well as R20, or any expenses that were reasonably incurred for meals. ${ }^{8}$ It goes on to say that the above allowances are payable to the witness for the period that the witness is absent from their home, to attend court. The travelling expenses are the same as in civil cases, being, for private transport, 92c per $\mathrm{km}$ in case of a motorcycle; or R1,30 per $\mathrm{km}$ in case of a motor vehicle, calculated along the shortest route. ${ }^{9}$ In the case of a witness making use of public transport, the travelling expenses are 'an amount equal to the fare for the least expensive transport along the shortest route'. ${ }^{10}$ The income forfeiture is also the same as in civil cases.

Now one must look at the witness fees and allowances payable to a psychiatrist or clinical psychologist to appear in court. The subsistence amount includes: Any expenses if the witness needs to hire accommodation for the night, as well as any expenses that were reasonably incurred for meals. It goes on to say that the above allowances are payable to the witness for the period that the witness is absent from their home, to attend court. The travelling costs are the same as mentioned above for witnesses in civil and criminal cases.

5 South African Medical Association Witness fees payable: Civil and criminal cases, 2012, 1.

6 As above.

7 SAMA (n 5).

8 SAMA (n 5) 2.

9 As above.

10 SAMA (n 5) 2. 
The remuneration of psychiatrists and psychologists is where the fees differ from witnesses in civil and criminal cases. The remuneration of these medical professionals is set out as follows: That 'a psychiatrist who is appointed by the court in terms of section 79(1) of the Criminal Procedure Act to enquire into the mental condition of an accused and who is not in the full-time service of the State, shall be compensated for giving evidence in court from public funds at the following rates', 11 either R3500 a day, or R2000 for evidence given in the morning, or lastly R1500 for evidence given in the afternoon. ${ }^{12}$

The information provided herein regarding costs was taken from a 2012 article from the South African Medical Association ${ }^{13}$ and lays the basis for the question to be asked, namely whether the costs of medical expert witnesses negatively affects those who cannot afford one.

\subsection{Effect of costs on those who cannot afford an expert witness}

As can be seen from the above, expert witnesses are most definitely not free. The costs associated with them can be too costly for a lowearning litigant to pay, especially if it is in addition to the legal fees involved.

It is common knowledge that South Africa has an alarmingly high unemployment rate and is a country that is plagued by poverty. In a study done by Stats SA, it was found that in 2015 more than half of South Africans were poor, the poverty rate is $55.5 \% .^{14}$ This means that the earning capacity of almost 30.4 million people is extremely low, as they are living in poverty. ${ }^{15}$

Due to the fact that the unemployment rate in South Africa is currently at $26.7 \%,{ }^{16}$ and the poverty rate is sitting at approximately $55.5 \%$, it is clear that if people that are unemployed or do fall into the $55.5 \%$ poverty rate require legal help, and the assistance of an expert witness could greatly enhance their case, they cannot afford one.

There is currently no case law in which it was said that not having an expert witness detrimentally affected the outcome of the case. Due to this fact, I will instead look a case law where medical expert witnesses were invaluable to the outcome of the case. The reason for

11 SAMA (n 5 ) 3.

12 As above.

13 SAMA (n 5) 3:

14 STATSSA 'Poverty on the rise in South Africa' 22 August 2017 http://www. statssa.gov.za/? $\mathrm{p}=10334$ (accessed 17 March 2018).

15 STATSSA (n 14).

16 Trading Economics 'South Africa unemployment rate' Stefanie Moya 15 May 2018 https://tradingeconomics.com/south-africa/unemployment-rate (accessed 17 March 2018). 
this is because I can then prove the point I am attempting to make, being that the cost aspect of medical expert witnesses negatively affects those who cannot afford one.

In an article on Health 24, it was said that,

Most private citizens can't afford to hire an expert, however much it might help their case. Rich defendants, however, can bring in as many experts as they wish. ${ }^{17}$

An example of this is the Oscar Pistorius case, a rich defendant who was able to bring as many expert witnesses as he liked.

There are multiple cases where expert witnesses have been of great assistance to a court case. Specifically looking at psychiatrists and clinical psychologists who are asked to give evidence in a case regarding the mental condition of an accused, it has already been discussed that these medical professionals come at a price. Yet, often their expertise is invaluable in the determination of the outcome of a case.

\subsubsection{Case law}

An example of evidence given with regards to the mental conditions of an accused can be seen in the case of $S v$ Pieterse. ${ }^{18}$ This case dealt with a psychopathic paedophile and it involved a psychiatrist evaluating and giving evidence as to the results of the accused's mental condition at the time the crime was committed. The psychiatrist found and told the court that the accused had full cognition at the time the crime was committed as well as conation. This then leads the court to furnish a guilty verdict as the individual was charged with murder. ${ }^{19}$

Another case, in which the expert evidence of a medical professional was extremely useful in the outcome of the case, was $S$ $v$ Kavin. ${ }^{20}$ This case involved a father who suffered from reactive depression who shot and killed his family. In this case medical professionals, namely three psychiatrists evaluated Kavin and they provided the court with evidence of Kavin's mental condition. They told the court that, at the time of the shooting, Kavin could distinguish between right and wrong, but he lacked conation. They referred to a so-called irresistible impulse, which meant that Kavin

17 Health 24 'The state of expert evidence in SA courts' 7 September 2015 https: / / www. health24.com/Columnists/The-state-of-expert-evidence-in-SA-courts20150907 (accessed 19 March 2018).

18 S v Pieterse 1982 (3) SA 678(A).

19 As above.

20 S v Kavin 1978(2) SA 731(W). 
had no willpower to resist and was therefore acquitted but committed to a mental institution. ${ }^{21}$

As can be seen from the above two cases, the role of expert witnesses is often of utmost importance with regards to the outcome of a case. If an individual is unable to afford such a medical professional to give expert testimony at a hearing, it is quite possible that this will negatively affect the outcome of the case, as opposed to the possible outcome if the parties had been able to afford an expert witness who could then lead evidence which would assist the parties.

It can thus be said that there is a high possibility that those who cannot afford to acquire an expert witness, specifically a medical one, can be negatively affected as opposed to those who can afford one.

\section{Determining whether it should be mandatory for medical professionals who are experts in their field to commit themselves to be available pro bono for a certain period of time each year as expert witnesses}

\subsection{Pro bono work}

According to the Law Society of South Africa, attorneys are required to give of themselves 24 hours per calendar year to do pro bono work. ${ }^{22}$ In looking at the meaning of 'pro bono' it can be seen that the direct Latin translation means, for the public good. ${ }^{23}$ Generally, pro bono means that professionals provide services free of charge to clients who are poverty stricken, or non-profit or charitable organisations. $^{24}$

The idea put forward is the possibility that medical professionals should give of themselves, also 24 hours per calendar year to be used as expert witnesses. Outside of the 24 hours, the normal rates would apply.

The reason for this idea is due to the fact that, as has been seen above, expert witnesses can be unaffordable for the many in South

21 Kavin (n 20):

22 Law Society of South Africa 'Getting legal assistance' http://www.lssa.org.za/ public/getting-legal-assistance (accessed 4 April 2018).

23 Investopedia 'What does “pro bono” really mean?’ Stan Murray 27 November 2017 https://www.investopedia.com/ask/answers/08/pro-bono.asp (accessed 4 April 2018).

24 As above. 
Africa who live below the poverty line or who are unemployed. This unaffordability coupled with the positive effect expert witnesses can have on the outcome of the case, leads to this idea of pro bono hours for medical professionals to be used as expert witnesses.

\subsection{Criterion for pro bono work for medical professionals to be used as expert witnesses}

It is obvious that the implementation of this idea would lead to unhappiness within the medical professional community due to the fact that they would be losing income to appear before a court without being remunerated.

A second problem is that it has to be decided which cases warrant a medical expert witness and which cases can do without.

In order to attempt to answer these problems, one needs to look at the weighing up between income and community service. Secondly one needs to look at the possible development of criteria to determine when a medical expert witness is needed so as not to waste the time of all parties involved and allow a medical expert to be used in a case when they could be of more use in another.

\subsubsection{Income $v$ community service}

A problem that would arise if medical professionals were required to give of themselves 24 hours per calendar year to be used as an expert witness would be the issue of loss of earnings for the 24 hours they were in court.

The average hourly salary for a doctor is R334. ${ }^{25}$ If a doctor works from $8 \mathrm{am}-5 \mathrm{pm}$, as most doctors do, this would mean that the daily income of a doctor would be approximately R3006. It is understandable that a doctor would not want to lose R3006 because he or she is sitting in court as an expert witness. There is also no way that this result can be avoided if the pro bono hours were to be implemented. Ultimately the truth is that the 24 hours spent doing pro bono work would result in a loss of earnings.

The question, however, is whether it can be justified to have medical professionals losing income in order to assist in what can be called, the greater good. This greater good would be assisting people who cannot afford to call an expert witness unless it is free of charge.

Ultimately one has to weigh up the importance of income and the importance of community service. In a country like South Africa, one

25 Pay Scale 'Physician / Doctor, General Practice Salary' 19 May 2018 https: / www. payscale.com/research/ZA/Job=Physician_\%2F_Doctor\%2C_General_Practice/ Salary (accessed 8 April 2018). 
which is rife with unemployment and poverty and one which is still trying to recover from its past, it is clear that community service is important. South Africa needs basic services to be provided free of charge so as to attempt to lessen the gap between those who have money and means, and those who do not.

David Holness, in his article, ${ }^{26}$ speaks about the arguments for the introduction of mandatory pro bono work. Although this article is regarding pro bono legal services for legal professionals, it is possible that the arguments for the introduction of mandatory pro bono work could also apply to medical professionals performing the service of expert witnesses.

The first of these arguments that could apply to medical professionals is that 'lawyers enjoy a profitable monopoly on the provision of legal services; it does not seem unduly burdensome to impose such an obligation in order to afford everyone in the country access to the courts'.27 If this is an argument for lawyers to engage in pro bono work, it seems even more fitting that medical professionals should do so too, due to the fact that often, medical professionals are also high earning members of society. Therefore, as the article says, it would not be unduly burdensome to impose such an obligation, due to the fact that it is providing people with access to expert witnesses who cannot afford them otherwise.

The second argument is that '... a failure to engage in such work violates the right to access to justice expressed in section 34 of the Constitution'. 28 It continues that: 29

Legal services are otherwise available only to those who are able and willing to pay relatively high professional charges. Low-income people are especially disadvantaged. The poor often go without legal services because the monetary and other costs of using the legal system are greater than their ability to bear them.

This extract sets out the crux of the argument for the introduction of pro bono hours for medical professionals to be used as expert witnesses. If the introduction of pro bono work for lawyers aids in access to justice, then surely the introduction of pro bono hours for medical professionals to be used as expert witnesses, does that same thing. By having access to expert witnesses free of charge, this can only aid in access to justice, and thus gives effect to section 34 of the Constitution. attorneys in South Africa' (2013) Potchefstroom Electronic Law Journal 16.

27 Holness (n 26) 145.

28 Holness (n 26) 146.

29 As above. 
For these reasons, it can be seen that in the income versus community service clash, community service must prevail in the South African context.

\subsubsection{Possible criteria}

The introduction of possible criteria on which the decision as to whether a medical expert witness is needed, is one that can only be postulated, due to the fact that there is no research on the matter.

It seems obvious that of the vast number of cases heard by South African courts per year, not every case can have, or needs an expert witness. If there was an implementation of pro bono hours for medical professionals to be used as expert witnesses, a system would be needed to determine when an expert is most appropriate so as to avoid experts being 'wasted' in court cases which do not require them.

This possible criterion would ultimately have to depend on the case at hand, and firstly whether there is a medical aspect to the case which requires the expert evidence of a medical professional. The party, who wishes to make use of a medical expert, would have to apply to the court or presiding judge and state the reasons why they believe a medical expert is necessary.

If the process involves the parties being able to use a medical expert if they want one, without even a simple process or criteria having been followed, this would lead to expert witnesses being 'wasted' on cases that they are not really vital to.

This process, however, as mentioned earlier is merely a postulation of what could possibly be introduced as a criterion, it is subject to flaws and it is subject to possible success, but without proper implementation, the actual outcome can only remain a speculation.

The information provided is that of pro bono work, the argument of income versus community service and the possible criteria for the use of an expert medical witness. Using this information and applying arguments for the introduction of mandatory pro bono work to medical professionals, could quite possibly lead to the conclusion that perhaps it should be mandatory for medical professionals to give of themselves 24 hours per calendar year to be used as expert witnesses. Although this idea is not without its flaws, namely the two mentioned above, it is conceivable to think that this concept is a possibility. 


\section{Examining whether the implementation of a panel of expert witnesses would help with regards to medical professionals doing pro bono work as expert witnesses}

\subsection{Panel of experts}

In his dissertation, Dr Scharf defines medical expert witnesses as follows: ${ }^{30}$

The MEW can be defined, as anyone (by implication in medicine - a medical practitioner) with special knowledge, skill, experience, training or education in a particular field or discipline, that permit him or her to testify to an opinion that will aid a judge in resolving a question that is beyond the understanding or competence of lay persons.

The above definition explains what a medical expert witness is and is vital in the explanation of a panel of expert witnesses. Simply put, a panel of expert witnesses means a group of individuals who are experts in their respective fields, forming a panel of experts to be used when required by parties.

Parties will then essentially pick an expert that they need for their case from that panel.

Of importance to this article is an explanation of a panel of medical expert witnesses. A panel of medical expert witnesses is not much different to a panel of experts, the difference being that a panel of medical experts is made up specifically of medical professionals, such as doctors, psychiatrists and psychologists to name a few. These experts will have prior training as to how to conduct themselves while in court and to ensure that they are not biased in their testimony. This aspect will be further discussed below.

\subsection{Would a panel assist in the implementation of pro bono legal work of medical professionals?}

The question is now posed as to whether the panel of expert witnesses would assist in the implementation of pro bono legal work for medical professions?

As discussed above, the pro bono work would require medical professionals to give of themselves 24 hours per calendar year to be used as expert witnesses. The introduction of a panel of medical

30 GM Scharf 'The medico-legal pitfalls of the medical expert witness' unpublished Masters of Law dissertation, University of South Africa, 2014 at 17 (on file with the author). 
expert witnesses could very possibly assist in the implementation of the proposed pro bono work, due to the fact that medical professionals may view the panel as a means to further their knowledge of the law and, although providing the service free of charge and losing income, they may relish in the legal knowledge they gain from being a part of the panel. This is, however, mere speculation. Due to the fact that there are no pro bono legal hours set for medical practitioners and no panel of medical experts, the ideas set out in this paper do not have a factual basis, and are, as such, just ideas.

The more likely answer is that the introduction of a panel of medical expert witnesses will have no bearing on the implementation of the pro bono legal hours for medical practitioners, as those who do join the proposed panel will be paid and it can be said that the panel and the pro bono hours are two ideas that are far removed from one another. It is unlikely that the majority of medical professionals will choose advancing their legal knowledge over losing a day's worth of income, especially those highly qualified specialists, such as orthopaedic and neurosurgeons, who make R1,220,838 per year ${ }^{31}$ and $\mathrm{R} 3,533,094$ per year ${ }^{32}$ respectively. This then translates into approximately R1699 per hour, for a neurosurgeon, which means the daily income loss will be over R15 000.

Another view that could support the implementation of a panel of medical expert witnesses is found where Dr Scharf mentions that witness doctors are often placed under a significant amount of stress when testifying against a fellow doctor. They fear that they could lose hospital privileges, ${ }^{33}$ and the witness doctors often believe that fellow doctors can make a mere mistake and not necessarily be negligent. ${ }^{34}$ There is clearly a negative stigma attached to those medical professionals who act as expert witnesses. However, it is possible that if every medical professional has to testify as an expert due to the implementation of the pro bono hours that the negative stigma attached to medical expert witnesses may be lessened if all medical professionals now know what it is like to testify.

Therefore, it can be seen that on examination of whether the panel of experts would assist in the implementation of the pro bono legal hours for medical professionals, there are only ideas that can be put forward. Due to the fact that neither the panel nor the pro bono hours currently exist, determining whether one would assist in the

31 Pay Scale 'Experienced orthopaedic surgeon salary' 26 May 2018 https:// www. payscale.com/research/ZA/Job=Orthopedic_Surgeon/Salary/c6b79c87/ Experienced (accessed 15 April 2018).

32 Salary Expert 'Neurosurgeon Salary in South Africa' https://www.salary expert.com/salary/job/neurosurgeon/south-africa (accessed 16 April 2018).

33 Scharf (n 30) 44.

34 As above. 
implementation of the other can only be based on ideas from the research that is available, such as the earnings of medical professionals and mere human nature.

\section{$5 \quad$ Would the implementation of a panel of expert witnesses help alleviate the problem of expert witnesses not having any basic legal knowledge?}

\subsection{Lack of basic legal knowledge}

Medical practitioners are not lawyers. Lawyers need medical practitioners as expert witnesses to help explain the often, complex medical aspects of certain matters to the court. An example of which is the case of Michael and Another $v$ Linksfield Park Clinic (Pty) Ltd and Another ${ }^{35}$ where it was said that 'the assessment of medical risks and benefits is a matter of clinical judgment which the court would not normally be able to make without expert evidence'. ${ }^{6}$

Due to the fact that medical practitioners are by no means lawyers, it follows that they will lack legal knowledge, such as court procedures and knowledge of the fact that, for criminal cases specifically, both factual and legal causation is required. These are some of the legal processes that a medical professional will not know, just as the lawyer will not know the medical aspects, which is why the medical expert is needed.

The problem is now that, due to a lack of legal knowledge, the medical expert can sometimes be more damaging to the case than helpful and if they fail to follow the correct procedure or presentation of their evidence, their evidence may be rejected.

\subsection{Alleviation of this problem via the implementation of a panel of experts}

The implementation of a panel of experts is an idea on its own, but a panel of experts will not alleviate the problem of the lack of basic legal knowledge that was discussed above. To alleviate this problem, it is necessary to require the experts on the panel to undergo basic legal training, so as to understand, for example, the court 
procedures. This will be done by looking at a dissertation by $\mathrm{Dr}$ Scharf. ${ }^{37}$

In his dissertation Dr Scharf is of the opinion that, 'medical witnesses should have legal training and insight into the legal and court procedures'. ${ }^{38}$ Throughout his writings he reiterates the need for medico legal training and using a book by Perry Hookman entitled 'Medical malpractice expert witnessing', he hypothesises that 'medical expert witnesses should have to undergo some training in the 'principles of medical law' as well as ethics'. 39

What is of the utmost importance is that a medical expert witness must not warrant a guess or give misleading information. It is vital that all the evidence that is given by a medical expert witness must be relevant to the case at hand. ${ }^{40}$ This is ultimately where legal training must present itself; it is required so as to ensure that the evidence given by the expert witness is not rejected because of the way they present it. 41

It has been said that there are certain criteria that will lead to the acceptance of the legal findings of scientific facts ${ }^{42}$ and that they are as follows:

(a) 'Theories are to be established, confirmed and must be relevant' 43

(b) 'The medical expert witness must understand the theory and science around it' 44

(c) 'Medical scientific principles must be correctly applied to the facts of the case, 45

(d) 'It must be understandable in and to the court' 46

(e) 'Correctness of the witness's presentation is essential' 47

(f) 'Credibility' 48

Many of the criteria above can be fulfilled by legal training. The need for theories to be relevant and confirmed is something a medical practitioner will not know unless they are told about it prior to taking the stand, thus basic legal training would stop this problem from arising. The criteria that the evidence given to the court must be understandable in and to the court can also be a problem, the reason being that a judge and lawyers will not understand complex medical terms which are second nature to a medical practitioner, and it is a 
negative blow for the case if the witness must constantly be asked to repeat himself in a manner the court can understand. If medical witnesses undergo basic legal training they will possess this knowledge and this problem will be alleviated. All of the abovementioned criteria can be met by providing a witness with basic legal training, which would be a necessary requirement for the panel of expert witnesses.

Therefore, it can be seen from the above that the introduction of a panel of medical expert witnesses would not be successful unless the members of the panel were required to under basic legal training to ensure that they do not cause more harm to a case than good.

\section{Determining whether the implementation of a panel of expert witnesses who have undergone basic legal training would help alleviate the so called 'hired gun phenomenon}

\subsection{Hired gun phenomenon}

Judges have been complaining about expert witnesses being biased for a significant period of time. To show this long period of complaints, one can look at the case of Lord Arbinger $v$ Ashton, ${ }^{49}$ in which the following was said

Undoubtedly there is a natural bias to do something serviceable for those who employ you and adequately remunerate you. It is very natural, and it is so effectual that we constantly see persons, instead of considering themselves witness, rather consider themselves as the paid agents of the persons who employ them.

It is now one hundred and forty-five years later, and it can be said that there is still a problem with witness bias. This witness bias can be called the 'hired gun phenomenon' ${ }^{50}$ Expert witnesses are hired by legal practitioners in order to assist them in proving or disproving their respective cases to the court. It is obvious that when hiring an expert, this will only be done when the expert can be of assistance to the case and its success. This raises the issue of witness bias. When an expert is hired to assist in a case, they may 'try to manipulate the situation so as to give an opinion aimed at advancing the case of those who instruct him or her, instead of placing an independent and unbiased defensible theory before the court'. 51

49 Lord Arbinger v Ashton (1873) 17 LR Eq 358.

50 H Lerm 'Beware the hired gun' Are expert witnesses unbiased?' (2015) De Rebus 36-38.

51 Lerm (n 50) 2. 
In order to counter this, there has been a set of rules established, of all these rules, the one which was ultimately excepted by South African writers was the set of rules designed by Creswell $\mathrm{J}$ in the National Justice Compania Naviera. ${ }^{52}$ These rules are listed below:

(1) Expert evidence presented to the court should be and should be seen to be, the independent product of the expert uninfluenced as to form or content by the exigencies of litigation.

(2) An expert witness should provide independent assistance to the court by way of objective, unbiased opinion in relation to matters within his expertise ..., An expert witness should never assume the role of an advocate.

(3) An expert witness should state the facts or assumptions upon which his opinion is based. He should not omit to consider material facts which could detract from his concluded opinion.

(4) An expert should make it clear when a particular question or issue falls outside his expertise.

(5) if an expert's opinion is not properly researched because he considers that insufficient data is available, then this must be stated with an indication that the opinion is no more than a provisional one. ${ }^{53}$

What the above rules mean is this: 'an expert is required originality, objectivity and an unbiased assistance to the court'. ${ }^{4}$ When providing the court with evidence the witness must base everything they say on facts or assumptions. ${ }^{55}$ The above rules were then accepted by South African writers 'Zeffertt, Paizes \& Skeen The South African Law of Evidence 5ed', 56 and they were quoted in the case of Schneider NO and Others $\vee A A$ \& Another. ${ }^{57}$

In the Schneider case, the court said the following regarding an expert witness involved in this case

An expert comes to court to give the court the benefit of his or her expertise'. Turning to the responsibilities of an expert witness, the court found that he or she must provide 'the court with as objective and unbiased an opinion, based on his or her expertise ... An expert is not a hired gun who dispenses his or her expertise for the purposes of a particular case' nor does he or she 'assume the role of an advocate 58

As can be seen from the above, bias when it comes to witnesses is not a new issue; it is an issue that has reared its head for several years, and despite numerous attempts in the form of rules to quell the problem, it appears that it is still evident today. For this reason, I

52 National Justice Compania Naviera SA v Prudential Assurance Co Ltd (The Ikarian Reefer) (No 1) [1993] 2 Lloyd's Rep. 68 [QBD CC].

53 As above.

54 Lerm ( $\mathrm{n} 50) 2$.

55 As above.

56 Lerm (n 50) 2.

57 Schneider NO and Others v AA \& Another 2010 (5) SA 203 (WCC) at 211J-212B.

58 As above. 
propose that perhaps the basic legal training that will come hand in hand with the implementation of a panel of medical expert witnesses will be a strong contender in the conquering of the hired gun problem.

\subsection{Panel of expert witnesses alleviating the hired gun phenomenon}

As mentioned above, the panel of medical expert witnesses will involve mandatory basic legal training for those who are selected and placed on the panel. This basic legal training will include an understanding of the court processes, and of the utmost importance, it must include an awareness of the fact that an individual's expert evidence will be rejected by the court if it is not presented correctly.

The correct presentation includes the expert witness setting out the evidence in such a way that it is not biased. The evidence must in no way be predominantly one sided, it should be based solely on facts and assumptions. If a medical expert witness presents evidence with the sole purpose of ensuring that the side they represent is successful, there is a high possibility that their evidence will be rejected, but there is also another problem, which relates to a judge and their reception of the evidence. This problem was set out in the Scottish case of Dingley $v$ The Chief Constable, Strathclyde Police ${ }^{59}$ and was cited in the South African case of Oppelt $v$ Department of Health, Western Cape. ${ }^{60}$ The following was said:

[O]ne cannot entirely discount the risk that by immersing himself in every detail and by looking deeply into the minds of the experts, a judge may be seduced into a position where he applies to the expert evidence the standards which the expert himself will apply to the question whether a particular thesis has been proved or disproved - instead of assessing, as a judge must do, where the balance of probabilities lies on a review of the whole of the evidence.

This extract could be the basis for the idea that if a witness does present evidence in a certain manner, it may also affect the judge's objectivity, although the judge should be aware of the possibility if this and guard against it, there is the possibility that a judge, who has no knowledge of any medical facts, could be inclined to take the evidence presented by a medical expert witness, and base his decision solely on that. Despite the fact that case law has set out that judges should come to a decision based on their own judgement, having taken into account all the evidence presented, including that of experts the problem still persists. In an article written by TB Barlow, the following was said: ${ }^{61}$

59 Dingley $v$ The Chief Constable, Strathclyde Police 2000 SC (HL) 77.

60 Oppelt $v$ Department of Health, Western Cape 2016 (1) SA 325 (CC).

61 TB Barlow 'Medical negligence resulting in death' (1948) THRHR 173-190. 
The question arises as to what regard the courts must pay to medical opinion. Must the courts make medical men the final judges ... or must they decide questions involving medical theory and dispute? ... The difficulty that faces the legal man is, however, that of judging upon the correctness of work that is highly skilled and beyond his providence. The practice of our courts has been to weigh up carefully the medical evidence presented to it by both sides but to keep the final decision in their own hands.

Judges, therefore, need to make decisions objectively and the final decision rests with the judges, after taking into account the evidence tendered by expert witnesses, whether medical or otherwise.

Despite the problem of evidence being rejected due to the nature of its presentation, it can be seen that there are other problems, one of which can be the judge as shown above.

These are but a few of the possible problems faced when an expert witness presents evidence in a biased manner. The proposed basic legal training that accompanies the proposed panel of expert witnesses could possibly alleviate the hired gun phenomenon and the problems that flow from it. It could do so because this basic legal training would inform medical experts on how to present evidence in the correct manner and warn them of the consequences of noncompliance with these rules.

In this way, the medical experts will have sufficient knowledge of the legal process to present evidence in the correct manner and thus alleviate the problems that follow a biased witness's testimony.

\section{International views on panels of expert witnesses and legal training}

\subsection{The medical expert witness and legal training in other legal systems}

The medical expert witness is used in many legal systems across the world. Although this article focuses on South African medical expert witnesses and the proposed implementation of a panel of expert witnesses accompanied by legal training, it is important to look at the views of other countries on the matter. Looking at other legal systems will help one to get a holistic view of the medical expert witness.

To begin, in Australia, it has been said that medical expert witnesses must 'undergo training and accreditation'. ${ }^{62}$ In the USA it has been said that: 
In future some form of legal education and training will have to take place to set a minimum standard. Guidelines must then also be given for acceptable testimony, ensuring that it is conducted fairly, reasonably and in good faith. ${ }^{63}$

In the United Kingdom, it has been said that medical expert witnesses should partake in some form of training or a course and then be registered as a medical expert witness after this has taken place. ${ }^{64}$ Courses for medical expert witnesses have been initiated in the UK, ${ }^{65}$ and it has also been recommended that medical expert witnesses should take the time and put in the effort to get some form of legal training prior to taking the stand, this includes training on ethics relating to the legal profession. ${ }^{66}$

Further support for basic legal training of medical expert witnesses can be found in the American Academy of Paediatrics in a technical report released on expert witness participation, where it was set out that: "in 2006, the AAP graduating resident survey revealed that only $25 \%$ of residents reported that their training program provided adequate education on the expert witness process' ${ }^{67}$ It was then said that: ${ }^{68}$

Educating paediatric residents to be cognizant of the ethical obligation of paediatricians to participate in the legal process and have a rudimentary understanding of the guidelines of medico-legal participation is important.

It is clear from the above extracts from the AAP that in American legal systems, legal training is also said to be important for medical expert witnesses.

Another instance in which the US spoke of the importance of legal training is when the US Department of Justice's National Indian Country Training Initiative together with the International Association of Forensic Nurses, announced in 2015 that they would hold the Sexual Assault Nurse Examiners' Expert Witness Training. ${ }^{69}$

63 As above.

64 Scharf (n 30) 129.

65 Scharf (n 30) 136.

66 As above.

$67 \mathrm{~K}$ Sandeep and others 'Expert witness participation in civil and criminal proceedings' (2017) 139(3) American Academy of Pediatrics.

68 As above.

69 Forensic Healthcare Online 'LIVE TRAINING: SANE Expert Witness Training' 29 April 2015 https://www.forensichealth.com/2015/04/29/live-training-saneexpert-witness-training/ (accessed 30 May 2018). 
Lastly, from a country who is not seen as a big influencer as the UK or USA is, medical expert witness training is also done in Singapore. They have a medical expert witness training programme set for this year during the months of May, June and July $2018^{70}$ and they set out the following regarding the training:

The Medical Expert Witness Training Course 2018 is a joint collaboration between the Medical and Legal Profession of Singapore. This course aims to prepare Medical Professionals to be an effective medical expert witness in court. 71

It can be seen from the above that there are many legal systems who have noted the extreme importance of legal training of medical expert witnesses, and in some countries, the training can be seen as a prerequisite for being a medical expert witness. Perhaps it would be wise for South Africa to follow suit, for this reason, I have proposed the panel of expert witnesses that will be accompanied by basic legal training.

\subsection{International views on a panel of experts}

It is unfortunate that not a great deal of information is available regarding panels of expert witnesses in foreign jurisdictions, a possible reason for this could be because many countries do not have panels of experts implemented in their legal systems.

Although there are countries, such as America who have panels of experts, they are not necessarily panels of medical expert witnesses. The closest to a panel of medical expert witnesses that can be seen is The Forensic Panel, which consists of psychiatrists and psychologists who assess a person's mental state relating to legal issues. ${ }^{72}$ This, although it is a panel of medical experts, relates specifically to psychiatry. The panel proposed for South African in this dissertation is one which encompasses all types of medical professionals.

A holistic panel of expert witnesses can be found in the County of Los Angeles in America. The expert witnesses are listed in the County of Los Angeles Superior Court and consist of witnesses from a listed set of fields. ${ }^{73}$ This list includes medical experts, as well as experts not related to the medical field. Although it includes a panel of medical expert witnesses, it is not exclusively a panel of medical expert witnesses as this dissertation suggests. However, it is more

70 Academy of Medicine, Singapore 'Medical expert witness training 2018' 2018 https://ams.edu.sg/latest-news/medical-expert-witness-training-2018 (accessed 30 May 2018).

71 As above.

72 The Forensic Panel 'Forensic psychiatry' https://www.forensicpanel.com/ expert_services/psychiatry.html (accessed 30 May 2018).

73 County of Los Angeles Superior Court Panel of Expert Witnesses 7 May 2018 http: / /www.lacourt.org/division/criminal/pdf/witnesses.pdf (accessed 30 May 2018). 
than sufficient to use the panel used in Los Angeles as a means to show that the implementation of panels of expert witnesses have been done in a foreign jurisdiction and it seems this has been done with success.

It is important to note here the panel of medical experts that relate to the Road Accident Fund (RAF). Although this chapter relates to international views on panels of medical expert witnesses, it would be an error of judgement if one did not look at this panel. The RAF stated the following:

The Road Accident Fund requires the services of medical experts when conducting its defence on litigated claims. American Medical Association (AMA) trained doctors are also needed to perform AMA assessments and provide reports in order to finalise new amendment act claims on general damages. ${ }^{74}$

These experts will be required to, amongst other duties, have to 'give expert evidence on behalf of the RAF during trials'. ${ }^{75}$ Although this panel stands in South Africa, it does not fall into the proposed panel of experts as the RAF panel is exclusively for the RAF, whereas the proposed panel of medical experts does not have exclusivity attached to it. Any person requiring a medical expert witness, who can afford one, may make use of the panel.

To conclude based on all the above listed information, it can be seen that there are many foreign legal systems which provide for legal training for medical expert witnesses. Although some jurisdictions merely state that medical expert witnesses should preferably undergo training, others can be said to have made it a requirement. It can be seen that this legal training, something which seems to only be beneficial, is not properly regulated and enforced in countries all over the world. What is important to note is that South Africa may be far behind the countries who do propose such training, and is in dire need of implementing this training to alleviate the problems experienced when making use of medical expert witnesses.

It is unfortunate that there is not a vast array of sources to draw from when it comes to panels of expert witnesses. What is important is to look at the countries who have implemented such panels, despite the fact that these panels may not be identical to the panel proposed herein, because information can be drawn from these panels. By looking at foreign legal systems that do have panels of experts, South Africa could be advised on how to implement such a panel, as well as its regulation.

74 Road Accident Fund Compulsory Briefing Session RFB /2013/00026 28 August 2013 https://www.raf.co.za/Procurement/Documents/Briefing\%20session\%20presen tation\%20PANEL\%200F\%20MEDICAL\%20EXPERTS\%20FINAL\%2028\%20August\%202013. ppt (accessed 30 May 2018). 


\section{Conclusion}

The ideas proposed by this article relate directly to the medical profession. It can be seen that there are significant problems that are attached to the cost aspect of medical expert witnesses. Medical professionals, understandably, require a large sum of money to spend the day in court, but the problem that has been identified herein is that many people cannot afford medical experts, and this may impact on the outcome of the case. This is due to the fact that a medical expert witness testimony is often invaluable if presented correctly, and it results in an unfair advantage that the rich can bring as many experts as they like, and yet the so-called poor cannot do the same.

For the reasons listed above, the first proposal was introduced which relates to the implementation of pro bono hours for medical professionals. This is an idea, as with all proposals, that has both positive and negative accepts. These range from the positive aspect, being that it would allow poorer people to make use of experts, to the negative aspects, which include the loss of earnings for the medical professionals. In order for this idea to be implemented, it would have to involve a weighing up of the negatives against the positives. It would also have to involve reviews given by both the medical professionals and those involved in the legal field that has borne witness to cases where medical expert evidence has not been utilised due to the cost aspect. These are mere recommendations on the implementation of the pro bono hours, recommendations that cannot be dealt with in this article alone, but that are necessary.

The second aspect of this article relates to the implementation of a panel of medical expert witnesses. This is an idea that has been implemented in part in other countries, although not in an identical fashion to the one proposed herein. The definition of a panel of medical expert witnesses is one step of the process. The main purpose of the medical expert witness panel is to alleviate the problems that accompany medical expert witnesses, these problems being the lack of legal procedures and the hired gun phenomenon. The problems mentioned in this article can both be alleviated by requiring medical professionals, who sit on the panel, to undergo basic legal training. This would then lead to these experts knowing how to testify and understanding the processes relating to the court. By implementing mandatory legal training for medical professionals who sit on the panel, the implementation of a panel of expert witnesses could, in this way, alleviate the problems relating to a lack of basic legal knowledge that is being experienced in South Africa.

The importance of foreign jurisdictions relating to legal training and panels of expert witnesses is extremely important. The ideas proposed currently have no standing in South Africa, and if South Africa were to look at the possible implementation of these ideas, it 
would be vital to look at other jurisdictions that have implemented such ideas or have said that it is a preferable route to take. The reason it is so important to look at other jurisdictions is because it provides South Africa with the ability to compare and analyse. It allows South Africa the opportunity to see how other countries have gone about implementing such ideas, how they are regulated and how they are enforced. Most importantly, it allows South Africa to see how these ideas are working in those countries and examine the pros and cons. This can all be done before implementing these notions in our own country, and this first-hand insight is invaluable.

It must be reiterated that these proposed notions are just that, proposed notions, they are currently not in force in South Africa. The aim of this article is to show the current discrepancies when it comes to medical expert witnesses in the South African legal system, and to layout possible ways to alleviate these discrepancies.

It can be seen from the above article that these ideas, although simple in form, can have extreme consequences, both positive and negative, which cannot be ignored. Unfortunately, no definitive answer can be reached regarding the possible implementation of these ideas within this article. However, what can be said with certainty is that the discrepancies when it comes to medical expert witnesses cannot be overlooked and further extensive research needs to be conducted before these ideas can materialise into reality. 